\title{
The Main Features of the Historical Evolution of the Paralympic Movement in the Second Half of the 20th Century
}

ISSN: 2576-8875

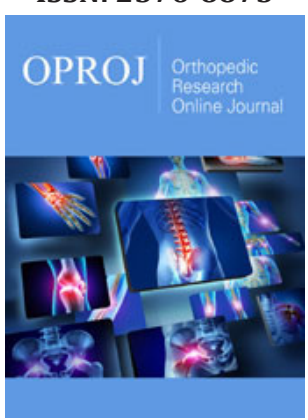

*Corresponding author: Stavrianos Iordanis, Faculty of Physical Education and Sport Science, Thessaloniki, Greece

Submission: 酸 January 11, 2021

Published: 眥February 25, 2021

Volume 8 - Issue 1

How to cite this article: Stavrianos Iordanis. The Main Features of the Historical Evolution of the Paralympic Movement in the Second Half of the 20th Century. Ortho Res Online J. 8(1). OPROJ. 000677. 2021. DOI: 10.31031/OPROJ.2021.08.000677

Copyright@: Stavrianos Iordanis, This article is distributed under the terms of the Creative Commons Attribution 4.0 International License, which permits unrestricted use and redistribution provided that the original author and source are credited.
Stavrianos Iordanis*

Faculty of Physical Education and Sport Science, Greece

\section{Introduction}

The Paralympic Games have covered a long way in the short time of the second half of the $20^{\text {th }}$ century and nowadays they are perceived as the largest international sport competition for athletes with disability. The Paralympic Games as an elite sport competition for athletes with disability have played a major role in changing society's attitudes towards disability, by focusing on the athlete's achievement rather than the disability itself, by accelerating the agenda of inclusion and by promoting the concept of accessibility in the urban environment (Nyland [1], Gold [2]).

The Paralympic Games have a significant influence, especially in those parts of the world where there are preconceptions and negative attitudes to the ideology regarding disability, by provoking changes of official attitude and public opinion of countries towards disability, of those countries that claim the accommodation of the Olympic and the Paralympic Games. Thus, we understand, that the Paralympics apart from an elite sport competition for athletes with disability are also an expression of a movement with ideals akin to Olympism (courage, self-confidence, determination, inspiration, equality, sportsmanship) that have engineered a transformation in the profile of people with disability from patients to athletes and then from athletes to equivalent citizens (Legg [3]). Furthermore, it is important to mention that the purpose of the Paralympic Movement is not only to promote sport, but mainly to use sports as a means for the continuous global promotion of the Paralympic Movement values (Peers [4]).

The purpose of this article is to mention and highlight the main features of the historical evolution of the Paralympic Movement in the second half of the $20^{\text {th }}$ century that led to this elite sport event which is, now, the second largest international sport event after the Olympic Games (Gold [2]).

\section{The initial seeds of paralympic movement}

The Paralympic Games were created due to the increased need in therapy and rehabilitation of the disabled injured in the Second World War. After the Second World War the traditional rehabilitation methods could not respond to the medical and psychological needs of the big number of soldiers and citizens with disability. Thus, in 1944, the British government founded for this purpose the National Spinal Injuries Center in Stoke Mandeville hospital in Aylesbury (Legg [3]). Director of this centre was Sir Ludwig Guttmann, a neurosurgeon who came to Britain as a refugee from Germany in 1939.

Guttmann, whose role was comparable to that of Pierre De Coubertin in reviving the Olympic Games and is considered the father of the Paralympic Movement, was the first to introduce the competitive sports (punchball exercises, rope climbing, wheelchair polo) at Stoke Mandeville hospital, as an integral part of the procedure of rehabilitation of people with disabilities in a period that the use of sport and exercise as a part of rehabilitation was unconventional (Pauw [5]). Actually, Guttmann believed that sports could be a way to help individuals with severe disability to live a healthier and happier life, to gain self-confidence 
and to achieve a degree of independence (Gold [2]). So, he formulated the idea of a sport festival for individuals with disability, which would foster the relations between patients. Moreover, the attitudes concerning capabilities of individuals with disability would be put on the table.

Initially the competitive games between the patients in Stoke Mandeville hospital took the form of ward-versus-ward competition and on 28 July 1948, the Stoke Mandeville Games started, with 16 competitors, 14 males and 2 females, between two teams, one of Stoke Mandeville and one of Star and Garter Home from Richmond, competing in archery (Legg [3]). These games are the first sport competition for wheelchair athletes while they are considered the forerunner of the Paralympic Games. So, under the leadership of Guttmann the use of sports as a therapeutic means for the restoration of fitness, strength, coordination, speed and social rehabilitation took an unprecedented and global dimension for all the categories of disabilities (Landry [6], Gold [2]).

The Stoke Mandeville Games were held annually mainly for individuals with paraplegia. In 1949 Stoke Mandeville hospital hosted an even larger event involving 60 competitors from five hospitals. During this meeting Guttmann gave a speech in which he hoped that this event would become international and acquire world fame just like the Olympic Games.

The number of sports in which the competitors took part in Stoke Mandeville Games also kept growing. Besides archery, gradually more sports were to be included such as lawn bowling, table tennis, shot put, javelin and club throw. In 1951 the Stoke Mandeville Games expanded with the participation of 126 patients from 11 hospitals competing in archery, netball, javelin and snooker (a cue sport akin to billiards) (Blauwet [7]).

A milestone date for the Paralympic Movement is 1952 when the Stoke Mandeville Games became an international sport event with the participation of a number of Dutch ex-military men (Wilson [8]). In these Games more than 130 athletes with disability competed in snooker, darts, archery and table tennis (Legg [3]). That was the year when an international Sport Movement for individuals with disability started to be created. The transition of the perception of sports as a tool useful only for rehabilitation purposes to a means of social integration and equal opportunities was accompanied by side benefits since individuals with disability began to receive recognition as athletes of a Sporting Movement which was far beyond the medical model of perception of disability (Blauwet [7]).

That international sport event developed more and more as in 1953 teams from Finland, France, Israel, the Netherlands and Canada took part in the Games. In 1955 a team from the USA also participated and in 1957 when a team from Australia participated, which was also the year that the Stoke Mandeville Games were commonly named "Paralympics", a pun combining "Paraplegia" and "Olympics” (Gold [2]).
In 1956, during the ceremonies at the Melbourne Olympics, the International Olympic Committee (IOC) awarded Guttmann with the Fearnley Cup for his outstanding achievement in the service of the Olympic Ideals (Gold [2]). That was a remarkable acknowledgement and appraisal in less than a decade since the beginning of the Stoke Mandeville Games.

Initially the vast majority of the Stoke Mandeville Games contestants were patients but soon the Games attracted former patients who lived independently. In the meantime the exercise routines became more and more specialized with an eye to promoting the health and the well-being of individuals with disability via sports; the Games became more professional reflecting the continuous development of the classification system, the advancement of specialization of the training process and coaches themselves, of the ongoing modifications of the manuals of the rules and regulations for every sport and the increase in the number of countries and participants in the Games.

\section{The official start of the paralympic games}

After Sir Guttmann's efforts and request directly towards the IOC, the IOC leadership agreed and in 1960 the International Stoke Mandeville Games took place for the first time in the same country, Italy, and city, Rome, as the Olympic Games, using the same venues as well (Blauwet [7]). These Games have gone down in history as the first official Paralympic Games with 400 athletes from 23 countries (Legg [3]), with the addition of wheelchair basketball, fencing, swimming and weightlifting (Pauw [5]). The Paralympic Games since then are held every 4 years following the Olympic Games. In the beginning it was not granted that the host city of the Olympic Games would host the Paralympic Games as well. Hosting the Paralympic Games depended on the good will of the city, the sponsor and the public funding which would cover the cost of the conducting of the Games. In 1964 the Paralympic Games were held in Tokyo, the host city of the Olympic Games, using the same facilities and being accommodated in the Olympic Village as well (Gold [2]). In addition, the name "Paralympics" with the prefix "Para", which is a Greek preposition "П $\alpha \alpha^{\prime}$ " meaning "parallel to the Olympics" and not what previously was wrongly perceived as short for paraplegic, was invented in the Tokyo Games for the first time (Legg [3]).

In the years to come there will be a diversion from the pattern initially established in the two previous Para lymphoid as the host countries of the Olympic Games refused to host the Paralympic Games. In 1968 the Paralympic Games were held in Tel Aviv, Israel and not in Mexico City (the host city of Olympics) which declined by claiming "technical difficulties" (Gold [2]). The officials of Mexico feared that the individuals with spinal cord injury would not stand the high altitudes and there weren't the necessary organizations to provide the appropriate know-how in order to help with hosting the individuals with disability. Nevertheless, the Israeli officials showed their interest to host the Paralympic Games that year because of 
the great number of people who ended up with a disability over that period due to the armed conflicts in the Middle East (Legg [3]). Finally, the Games were held in the Israel Foundation for Handicapped Children in Ramat Gar.

In 1972 the Paralympic Games were held in the University of Heidelberg and not in Munich (the host city of the Olympic Games), which alleged that the apartments used by Olympic athletes had been rented, for the period after the closing ceremony of Olympic Games and there was no other place available to host the Paralympic athletes. Respectively, the Paralympic Games in 1976 were held in Toronto and not in Montreal and in 1980 in Arnhem, Holland, instead of Moscow, since the Soviet Union (the host city of the Olympics) didn't have any sport organizations providing sport opportunities for citizens with disability and thus they didn't consider themselves suitable to host the Paralympic Games.

The Toronto Paralympic Games in 1976 pioneered by including for the very first-time athletes with other forms of disability. Specifically, athletes with amputations, visual impairments, and Les Autres (other forms of disability) took part in the Games. This addition of athletes with other forms of disability in the Games had a significant and long-term impact on the Paralympic Games, since they demanded that the name of the Games was changed from "Paralympics" to the "Olympiad for the Physically Disabled". This was requested because the word "Paralympic" had the connotation of Paraplegic Games and thus, athletes with visual impairment and amputations felt that they were excluded (Legg [3]). This naming change never happened and eventually the term "Paralympic Games" was selected as the official term of the Games in 1988 with the Greek preposition "Para" meaning "Parallel" to illustrate how the Paralympic and Olympic Movement exist side by side as mentioned before. In 1980 athletes with cerebral palsy were included in the Summer Paralympic Games in Arnhem as well (Legg [3]).

The year 1976 was also significant because the Winter Paralympic Games were held for the first time in Ornskoldsvik, Sweden. Then the Winter Paralympic Games were called Winter Olympic Games for the Disabled (Legg [3]). The initial Winter Paralympic Games were not held in the host countries and cities of the Winter Olympic Games, so in 1976 they were held in Ornskoldsvik instead of Innsbruck, Austria, while the following Games in 1980 were held in Geilo, Norway and not in Lake Placid, USA, and the Paralympic Games of 1984 and 1988, instead of being held in Los Angeles and Seoul respectively, were held in Innsbruck. The Winter Paralympic Games were held in the same cities as the Winter Olympics for the very first time in both 1992 and 1994; in Albertville, France, in 1992, in Lillehammer, Norway in 1994. This then began the practice of Paralympic Winter Games being held in the same cities as the Winter Olympic Games (Legg [3]).

The year 1984 is regarded as a milestone year for the Paralympic sports since in the Summer Olympic Games in Los Angeles and in the Winter Olympic Games in Sarajevo athletes with disability were invited to compete in demonstration events in the Olympic Games in wheelchair athletics and alpine skiing correspondingly (Legg [3]). These demonstration events were held till the Olympic Games in Athens in 2004 (Legg [3]). The Summer Paralympics in 1984 would be held for the first time in two separate locations. The USA agreed to host the Games but not in the host Olympic city. Instead, they were to be split between New York and the University of Illinois at Champain, an arrangement that foundered when the latter withdrew, due to financial problems, just four months before the Games. Finally, after the cancellation of the University of Illinois, the events for athletes with cerebral palsy, amputations and visual impairments were held in New York and the wheelchair events in Stoke Mandeville hospital in Aylesbury, UK (Legg [3]). Ironically, these were the first Games that the IOC officially recognized them as the Paralympics.

\section{The modern paralympic games}

The year 1988 is also a milestone date for the Paralympic Movement. The Paralympic Games in Seoul are perceived as the inception of the modern Paralympic Games. This is, partly, why they were held in the same venues as the Summer Olympic Games after many years. It is remarkable to notice that this arrangement has since then been established and since 2000 both Games have been included in the same bid (Legg [3]). They also received spectacular Opening and Closing Ceremonies similar to the Summer Olympic Games, watched by 75,000 spectators. Furthermore, these Games were different in their perspective, having a more sport-based focus and, to some extent, rejecting the medical model (Legg [3]).

Another reason that the Games in Seoul have special significance for the Paralympic Movement is the change of the logo of the Paralympic Games. Before 1988 a variety of logos reflecting the Olympic rings had been adopted but the Seoul Organizing Committee replaced the 5 rings with 5 Tae Geuks in 1988, which are a traditional Korean Symbol, in the Olympic colours (blue, black, red, yellow and green). When the International Paralympic Committee (IPC) was founded in 1989 the five Tae Geuks were incorporated as its official symbol. However, in 1991 the British Olympic Committee protested about the logo with the 5 Tae Geuks claiming that it was too close to the Olympic logo and that it would be a negative factor in attracting sponsors and funding (Legg [3]).

Finally, the logo with the 5 Tae Geuks changed after the 1994 Winter Paralympic Games because it had already begun being used for the promotion of the Lillehammer Winter Paralympic Games. The new one included 3 Tae Geuks in blue, red and green instead of five. In 2003 the logo was ultimately modified replacing the Tae Geuks with Agitos (from the Latin word Agito meaning "I move") used for the first time in the Athens Paralympic Games in 2004 with the new motto "Spirit in Motion" (Gold [2]).

In 1996, in the Barcelona Games, the Paralympic athletes would have the same treatment as the Olympic athletes and would have their custom-designed Opening and Closing ceremonies as there 
was a separate Division in the Olympic Games Organizing Committee responsible for organizing the Paralympic Games. Athletes with mental disability were included in the Atlanta Paralympic Games in 1996 for the first time, but after the Sydney Games in 2000, when cases with athletes pretending mental disability were exposed, these games were no more included in the Paralympic Games (Legg [3]). The Paralympic Games in Sydney in 2000 were unique because they broke all the previous sales records with 1.1 million tickets and there were many outstanding performances from the athletes that confirmed that the Paralympic Games is a big and elite sport event with a worldwide fame. Each one of the Paralympic Games that followed, that is, in Athens (2004), Torino (2006), Beijing (2008) and so forth, reveals the great development of the Games, the astonishing performances of the athletes, the improvement of the organizational quality and the increasing awareness towards disability.

\section{A brief report on the organizational structure of the paralympic games}

Until 1952 the Stoke Mandeville Games were organized by Dr Guttmann and the Stoke Mandeville hospital staff (www. paralympic.org). But as the Games grew and took an international dimension, the demand for greater professionalism on behalf of the organization, funding and management of the international sport for the disabled had become clear. So, in 1959 the International Stoke Mandeville Games Committee (ISMGC) was founded, and it was responsible for the Games organization until the 1968 Games. In 1972 the ISMGC was amended to the International Stoke Mandeville Federation and took charge of the Games until 1984 [9].

In 1961 an International Working Group was set up with the objective to establish an umbrella organization for all disabilities and in the future to act as a coordinating committee of the Games. This objective was achieved in 1964 with the foundation of the International Sport Organization for the Disabled (ISOD). The ISOD provided sport opportunities to individuals who couldn't be linked to ISMGC, that is, athletes with visual impairment, amputation and cerebral palsy [9].

The need for one governing body responsible for coordinating the Games and the request of the IOC to correspond and collaborate with one umbrella organization led to the creation of the International Coordinating Committee of the World Sports Organizations for the Disabled (ICC) in 1982 [9]. The ICC gave the disabled Sports Movement a single, unified voice for the first time. However, the member nations of ICC demanded more national and regional representation in the organization. This led to the foundation of a new organization with democratically elected administration, the International Paralympic Committee (IPC) in 1989 [9]. The IPC since 1992 is the sole coordinating body for Paralympic Sports, recognized by IOC.

\section{Conclusion}

This article has attempted to present the historical key elements of the Paralympic Movement in the second half of the $20^{\text {th }}$ century that led from a small sport competition with only 16 competitors, to an elite international sport event with numerous athletes competing from several countries. It has also been attempted to demonstrate how the Paralympic Movement through the Paralympic Games manages to configure an encouraging environment towards disability.

In the second half of the $20^{\text {th }}$ century the Paralympic Games have developed dramatically. Over that period, they have spread geographically, new sports have been included, a wider range of disabilities has been introduced and it has been made clear that sports are available to all. They also have managed to convert individuals with disability to elite athletes enjoying treatment and approval comparable to Olympic athletes. Furthermore, the Paralympic Games inclusion in the Olympic Games bidding process ensures the use of the Olympic facilities featuring high standards, a barrier free environment, challenging a society that welcomes diversity.

Unequivocally, the Paralympic Games, being the best “ ambassador" of disability issues towards society, have had a remarkable impact on disability, Disability Sports and society $s$ attitude toward disability. This positive impact along with the ongoing growth of the Paralympic Games will definitely keep challenging our society.

\section{References}

1. Nyland J (2009) The paralympic movement: Addition by subtraction. Journal of Orthopaedic \& Sports Physical Therapy 39(4): 243-245.

2. Gold J, Gold M (2007) Access for all: The rise of the paralympic games. The Journal of the Royal Society for the Promotion of Health 127(3): 133-141.

3. Legg D, Steadward R (2011) The paralympic games and 60 years of change (1948-2008): Unification and restructuring from a disability and medical model to sport-based competition. Sports In Society 14(9): $1099-1115$

4. Peers D (2009) Disempowering paralympic histories: Absent athletes and disabling discourses. Disability \& Society 24(5): 653-655.

5. Pauw K (2012) A historical perspective of the paralympic games. Journal of Physical Education, Recreation \& Dance 83(3): 21-31.

6. Landry F (1995) Paralympic games and social integration. In: Moragas M \& Botella M (Eds.), The keys to Success: The social, sporting, economic and communications impact of Barcelona, pp. 124-138.

7. Blauwet C, Willick S (2012) The paralympic movement: Using sports to promote health, disability rights, and social integration for athletes with disabilities. PM\&R 4(11): 851-856.

8. Wilson P, Clayton G (2010) Sports and Disability. PM\&R 2(3): 46-54.

9. (2021) Paralympics-History of the Movement. Espanol. 